\title{
Spatial pattern and its evolution of Chinese provincial population: Methods and empirical study
}

\author{
DENG Yu ${ }^{1,2}$, LIU Shenghe ${ }^{1,2}$, CAI Jianming ${ }^{1,2},{ }^{*}$ LU Xi ${ }^{3}$, Chris P NIELSEN ${ }^{3}$
}

1. Institute of Geographic Sciences and Natural Resources Research, CAS, Beijing 100101, China;2. Key Laboratory of Regional Sustainable Development Modeling, CAS, Beijing 100101, China; 3. School of Engineering and Applied Sciences, Harvard Cambridge, MA 02138, USA

Abstract: China has been experiencing an unprecedented urbanization process. In 2011, China's urban population reached 691 million with an urbanization rate of $51.27 \%$. Urbanization level is expected to increase to $70 \%$ in China in 2030 , reflecting the projection that nearly 300 million people would migrate from rural areas to urban areas over this period. At the same time, the total fertility rate of China's population is declining due to the combined effect of economic growth, environmental carrying capacity, and modern social consciousness. The Chinese government has loosened its "one-child policy" gradually by allowing childbearing couples to have the second child as long as either of them is from a one-child family. In such rapidly developing country, the natural growth and spatial migration will consistently reshape spatial pattern of population. An accurate prediction of the future spatial pattern of population and its evolution trend are critical to key policy-making processes and spatial planning in China including urbanization, land use development, ecological conservation and environmental protection. In this paper, a top-down method is developed to project the spatial distribution of China's future population with considerations of both natural population growth at provincial level and the provincial migration from 2010 to 2050. Building on this, the spatial pattern and evolution trend of Chinese provincial population are analyzed. The results suggested that the overall spatial pattern of Chinese population will be unlikely changed in next four decades, with the east area having the highest population density and followed by central area, northeast and west area. Four provinces in the east, Shanghai, Beijing, Tianjin and Jiangsu, will remain the top in terms of population density in China, and Xinjiang, Qinghai and Tibet will continue to have the lowest density of population. We introduced an index system to classify the Chinese provinces into three categories in terms of provincial population densities: Fast Changing Populated Region (FCPR), Low Changing Populated Region (LCPR) and Inactive Populated Region (IPR). In the FCPR, China's population is projected to continue to concentrate in net immigration leading type (NILT) area where receives nearly $99 \%$ of new accumulated floating population. Population densities of Shanghai, Beijing, Zhejiang will peak in 2030 , while the population density in Guangdong will keep increasing until 2035. Net emigration leading type (NELT) area will account for $75 \%$ of emigration population, including Henan, Anhui, Chongqing and Hubei. Natural growth will play a dominant role in natural growth leading type area, such as Liaoning and Shandong, because there will be few emigration population. Due to the large amount of moving-out labors and gradually declining fertility rates, population density of the LCPR region exhibits a downward trend, except for Fujian and Hainan. The majority of the western provinces will be likely to remain relatively low population density, with an average value of no more than 100 persons per $\mathrm{km}^{2}$.

Keywords: China; provincial; population; urbanization; migration; spatial pattern; natural growth

Received: 2014-06-06 Accepted: 2015-03-15

Foundation: Key Program of the National Natural Science Foundation of China, No.71433008; Key Research Program of the Chinese Academy of Sciences, No.KZZD-EW-06-04; National Natural Science Foundation of China, No.41271174; National Key Technology R\&D Program, No.2012BAI32B06; Beijing Planning of Philosophy and Social Science, No.13CSC011

Author: Deng Yu (1985-), PhD, specialized in urban and social geography. E-mail: dengy@igsnrr.ac.cn

*Corresponding author: Lu Xi (1979-), Research Associate and Lecturer, specialized in renewable energy and 
DOI: $10.1007 / s 11442-015-1248-x$

\section{Introduction}

In the past three decades, China has experienced a high speed of socioeconomic development, accompanied with dramatic changes in natural growth and migration of population (Zhang and Song, 2003). The annual natural growth rate between 2000 and 2010 was reported at $0.57 \%$ in China's 6th national census, significantly less than that for the 1990s. Low natural growth rate might imply a decline in the "demographic bonus", potentially weakening the economic growth in China (Ma and Zheng, 2011). Meanwhile, the amount of population migration reached 260 million, accounting for as high as $20 \%$ of total population in China in 2010 (NBS, 2001, 2011). Huge amount of migration raises concerns of social justice including equality in employment, education, housing as well as medical service, posing a great potential challenges to the society (Chen, 2012). A thorough investigation of the future spatial pattern of population and its evolutional trend is critical for the socioeconomic sustainable development in China (Liu et al., 2010).

There are three main methods in population forecasting: mathematical trend extrapolation, demographic-economic model, and cohort-component model (C-C model) (Andrew, 1984). Mathematical trend extrapolation relies on the pattern of historic population data to predict what will happen in the future (Keyfitz, 1968, 2005). This method assumes that the future growth of population follows the similar pattern with the past. The accuracy of population forecasting, therefore, is subject to the choice of baseline and underlying assumption (Nakicenovic, 2000). Demographic-economic model aims at forecasting population through linking population changes with economic conditions (Kenneth and Wendling, 1980; Thomas, 1981). The economic condition, involving the evaluation of interest rate, import-export demand and related policies, is equally complicated (Booth et al., 2006). This method is seldom applied for forecasting population on the national level. (Hyndman and Ullah, 2007). The $\mathrm{C}-\mathrm{C}$ model divides the population by age groups, and takes effects of human fertility, mortality and natural growth into consideration, thus it provides a relatively accurate prediction of population (Stauffer, 2002). The key for this method is parameterizing the model to reflect the social and geographical characteristics of the population. The C-C model has been adopted by the United Nations (UN) to routinely forecast the future country-level population in the world. To be discussed later in details, the UN's population forecasting for China demonstrated an impressive agreement with the data reported by China's national censuses conducted in 2000 and 2010.

In addition, population forecasting involves micro-level and macro-level strategies (Long, 1985). The micro-level strategy is a bottom-up approach, with the higher-level population derived from individual geographical regions at the lower level. In contrast, macro-level strategy decomposes the national population through mathematical methodology into that at lower level, such as province, prefecture-level city or county city. Micro-level strategy exhibits a good performance on forecasting the changes in the future distribution of population for individual areas (Bach and Schraml, 1982; Wood, 1982) but fails in 
considering the impact of changes from the larger background. Besides, building up a nationwide population model based on micro-level strategy is difficult in practice for two reasons. First, data for the demographic components may not be available for all counties. Second, the future population at regional level might be underestimated or overestimated deliberately in China in order to secure more favorable policies from the central government for local development (Gans 1999). Both of them impair accuracy of population forecasting using micro-level strategy at national level, resulting in the governmental sub-optimal decisions as to where to develop the infrastructure, to make investment and to allocate subsidies. The macro-level strategy has advantages in calculating population with diverse types and patterns from differing historical periods and geographical areas (Harris and Moore, 1980). The application of macro-level strategy reported in the earlier literature often took the country as whole, or divided the total population into data grids. Few literatures emphasized on population forecasting for the jurisdiction level of province or county, which is critical for policy-making process at macro level.

The present study is intended to explore the dynamic spatial pattern for the future population in China between 2010 and 2050. Macro level strategy was adopted in this study to forecast the natural growth and migration at provincial level. Data relevant to China's total population between 2010 and 2050 including total population, total urban population, and the urbanization rate on a national basis, are derived from the forecasting results using a $\mathrm{C}-\mathrm{C}$ model developed by the Department of Economic and Social Affairs under the UN. These data are used as constraints to cap the natural growth and migration of population at the provincial level. Data from the 5th and 6th China's national censuses conducted respectively in 2000 and 2010 provide a background of natural growth and migration of provincial population in China, serving an initial condition for this analysis.

Following this section, Section 2 describes data and methodology. The results are discussed in Section 3. Section 4 started with analyzing the spatial pattern and trend of Chinese provincial population. And an index system is introduced further to regionalize the changes in future spatial distribution of the population density, the ratio of accumulated netmigration to the peaking population, and accumulated natural population growth over the study period, with conclusion summarized in Section 5. The results reported in this analysis are expected to be helpful for a variety of key policy-making processes in China such as industrial development, ecological conservation, industrial upgrading and transfer, and environmental protection.

\section{Data and methodology}

Evolution of spatial distribution of the provincial population in China is attributed to a combined effects of natural growth and migration. Natural population growth for the past five years was tentatively extrapolated to the next five years, and then adjusted to make it in conformity with the UN's forecasted population for the entire nation. The initial growth rates of provincial population between 2000 and 2010 were derived from the 5th and 6th national censuses. Migration population for each province was estimated separately according to the future national migration and migration matrixes. The latter were predicted using a Markov chain approach. We selected to neglect the contribution of natural growth from the migration population based on two considerations. First, the 6th national census data suggested an 
evident increasing trend for the whole family migration which has no contribution to the natural growth. Another reason is rooted in the fact that fertility rates were calculated on account of only registered population (Zhu, 2011).

\subsection{Natural population growth}

At the national level, we adopted the results of population forecasting for China by the UN as constraints to China's future total population growth. Table 1 summarizes three key elements in the UN database forecasted from 2010 to 2050, including total population, urban population and the urbanization rate.

Table 1 Main indicators of population forecasting by the UN

\begin{tabular}{lccccccccc}
\hline & 2010 & 2015 & 2020 & 2025 & 2030 & 2035 & 2040 & 2045 & 2050 \\
\hline Total population & 133972.49 & 136974.3 & 138779.2 & 139525.6 & 139307.6 & 138158.8 & 136090.6 & 133176.8 & 129560.4 \\
Urban population & 669192.56 & 761579 & 846363 & 911804 & 957649 & 984446 & 998581 & 1004090 & 1001612 \\
Urbanization rate & 0.49 & 0.55 & 0.61 & 0.65 & 0.69 & 0.71 & 0.73 & 0.75 & 0.77 \\
\hline
\end{tabular}

Data source: World Population Prospects, the 2010 Revision

The process to predict population growth at provincial level involves three steps.

Step 1: Natural provincial growth rates between 2000 and 2010 were used as a first guess for the growth rates between 2010 and 2015. Population due to natural growth can be calculated using equation (1).

$$
P_{n, 2015}=P_{n, 2000} \times\left(1+R_{n, 2000}\right)^{5}
$$

where $R_{n, 2000 s}$ represents the natural population growth rate of a province on an average between 2000 and 2010; definitions of the other parameters and variables introduced here are summarized in Table 3.

Step 2: We adjust the forecasting results from Step 1 to ensure that the sum of provincial population matches the national population projected by the UN. The difference between them was allocated to each province based on its percentage of population to the national total. The process is described by equations (2)-(6).

$$
\begin{aligned}
& P_{\text {rese }, t}=\sum_{n=1}^{N} P_{n, t} \\
& \delta_{\mathrm{xan}, \mathrm{t}}=P_{\mathrm{LN}, 4}-P_{\mathrm{nam}, \mathrm{t}} \\
& \delta_{n, t}=\frac{\delta_{x a m, t}}{P_{x a m, t}} \times P_{n, t} \\
& P_{n, t}^{\prime}=P_{n, t}+\delta_{n, t}
\end{aligned}
$$

where $P_{n, t}$ is the population amount of province $n$ in year $t ; P_{\text {sum }, t}$ denotes the total provincial population in year $t ; P_{U N, t}$ represents the national population forecasting from the $\mathrm{UN} ; \delta_{\text {sum }, t}$ is the difference between $P_{\text {sum }, t}$ and $P_{U N, t} ; \delta_{n, t}$ denotes the fraction of difference $\left(\delta_{\text {sum }, t}\right)$ allocated to each province; $P^{\prime}{ }_{n, t}$ represents the improved population of province $n$ in year $t$.

Step 3: The natural growth rate for each province was then adjusted using results from Step 2. The updated growth rate is then used to extrapolate the population growth for the next five 
years. The process is expressed by equations (7) and (8):

$$
\begin{gathered}
R_{n, t}=\sqrt[5]{\frac{P_{n+1}^{\prime}}{P_{n+1}-1}}-1 \\
P_{n, t+5}=P_{n, t}^{\prime} \times\left(1+R_{k, t}\right)^{5}
\end{gathered}
$$

where $R_{n, t}$ represents the adjusted natural population growth rate; $P_{n, t+5}$ represents the first guess for the population of next five years, which will be adjusted by repeating Step 2.

\subsection{Migration}

\subsubsection{Migration at national level}

Urban population in China increased by 212.8 million from 2000 to 2010 . The corresponding urbanization rate rose from $36 \%$ in 2000 to $50 \%$ in 2010 . At national level, the migration consists of intra-urban migration and rural-to-urban migration, which accounted for 40 million and 74 million respectively in 2010. In the rural-to-urban transition, intra-province and inter-province migrations consisted of 40 million and 34 million population respectively. Rural-to-urban migration constitute the dominant component of inter-province migration $(80 \%)$, with the rest compensation of intra-urban migration (8.5 million, 20\%) (see Table 2). The inter-province migrations were estimated using equations using equations (9)-(12):

$$
\begin{gathered}
\Delta U P=U P_{t+1}-U P_{t} \\
\Delta M R=\Delta U P \times r_{1} \\
\Delta M R_{\text {nets }}=\Delta M R \times r_{2} \\
\Delta M_{\text {ints }}=\frac{\Delta M R_{\text {mast }}}{r_{3}}
\end{gathered}
$$

where $\triangle M R$ demonstrates the total population migrating from rural areas to urban areas;

\begin{tabular}{|c|c|c|c|c|c|c|c|}
\hline \multirow{3}{*}{ Year } & \multicolumn{7}{|c|}{ Registered residence (million) } \\
\hline & \multirow[b]{2}{*}{ Total } & \multicolumn{3}{|c|}{ Urban area } & \multicolumn{3}{|c|}{ Rural area } \\
\hline & & Subtotal & $\begin{array}{c}\text { Intra- } \\
\text { province }\end{array}$ & $\begin{array}{c}\text { Inter- } \\
\text { province }\end{array}$ & Subtotal & $\begin{array}{c}\text { Intra- } \\
\text { province }\end{array}$ & $\begin{array}{c}\text { Inter- } \\
\text { province }\end{array}$ \\
\hline Up to 2010 & 212.25 & 83.85 & 70.39 & 13.46 & 128.4 & 75.25 & 53.15 \\
\hline Up to 2000 & 98.12 & 43.39 & 37.93 & 5.46 & 54.74 & 35.44 & 19.30 \\
\hline $2000-2010$ & 114.13 & 40.47 & 32.46 & 8.01 & 73.66 & 39.81 & 33.85 \\
\hline
\end{tabular}
$\Delta M R_{\text {inter }}$ is the inter-provincial migration component of the total rural-to-urban migration $(\Delta M R) ; \Delta M_{\text {inter }}$ represents the total inter-provincial migration. $r_{1}$ is the ratio of $\Delta M R$ to changes in the urban population $(\Delta \mathrm{UP}) ; r_{2}$ is the ratio of $\Delta M R_{\text {inter }}$ to $\Delta M R ; r_{3}$ is the ratio of $\Delta M R_{\text {inter }}$ to $\Delta M_{\text {inter. }}$

Table 2 Net-migration population to the urban area at national level

Data source: The 5th National Population Census, 2000, and the 6th National Population Census, 2010 
Table 3 Definitions of variables or parameters used in this analysis

\begin{tabular}{cl}
\hline Parameters or variables & \\
\hline$R_{n, t}$ & Population natural growth rate in province $n$ for year $t$ \\
$P_{n, t}$ & Population amount for natural growth in province $n$ for year $t$ \\
$P_{n, t}^{\prime}$ & Improved population amount for natural growth in province $n$ for year $t$ \\
$\mathrm{UP}$ & Total urban population \\
$\Delta M R$ & Migration amounts from rural to urban area \\
$\Delta N M$ & Net inter-provincial migration matrix \\
$T P M$ & Net transition probability matrix \\
$M$ & Migration amount \\
$\Delta M$ & Total net migration amounts \\
$\delta_{n, t}$ & Difference between provincial population projection and the data from the UNs in \\
$T P_{n, t}$ & province $n$ for year $t$ \\
$S_{n, t}$ & Total population amount in province $n$ for year $t$ \\
$D P_{n, t}$ & Area of province in province $n$ for year $t$ \\
$A_{n}$ & Population density of province in province $n$ for year $t$ \\
$B_{n}$ & Variance of population density of province $n$ \\
$C_{n}$ & Ratio of new accumulated net-migration to maximum of the total population in province \\
& Ratio of new accumulated net-migration to maximum of natural growth population of \\
province $n$
\end{tabular}

\subsubsection{Migration at provincial level}

The approach of Markov chain was adopted to estimate the net-transition-probability migration matrix among provinces for the next five years. Constructing an initial probability matrix involves two steps: First, the net inter-provincial migration matrix between every two provinces between 2000 and 2010 was derived from the 5th and 6th national censuses; and second, this net inter-provincial migration matrix was divided by the net total migration amounts. This process is achieved through following equations (13)-(15):

$$
\begin{aligned}
& \Delta N M_{\text {ints }}=M_{\text {ister,2010 }}-M_{\text {iats, } 2000} \\
& T P M=\frac{\Delta N M_{\text {intre }}}{\Delta M_{\text {instr }}} \\
& M_{n, t}=T P M \times \Delta M_{\text {inte }}
\end{aligned}
$$

where $M_{\text {inter,2000 }}$ represents the total inter-provincial migration between every two provinces up to 2000 , and $M_{\text {inter,2010 }}$ for the total inter-provincial migration up to 2010 . $\Delta N M_{\text {inter }}$ denotes the net inter-provincial migration matrix between 2000 and 2010; TPM is the net transition probability matrix; $M_{n, t}$ is the migration of province $n$ in year $t$. Net inter-provincial migration for individual provinces can be calculated by multiplying net transition probability matrix with the national net inter-provincial migration population in the same years.

\subsection{Spatial pattern of the future provincial population}

As shown in equation (16), total provincial population equals the natural growth population plus inter-provincial migration. Population density for a specific province can be further 
derived from its total population dividing its area (equation 17). Here, we introduce three indicators constructed in equations (18)-(20), namely the population density (A), the ratio of accumulated net-migration to the peaking population (B), and accumulated natural population growth (C) over the study period to classify the changes of future pattern of provincial population. All provinces of China can be divided into three types of region: fast changing populated region (FCPR), slow changing populated region (SCPR) and inactive populated region (IPR). Sub-classes for the FCPR and the SCPR include net-immigration leading type (NILT), net-emigration leading type (NELT) and natural growth leading type (GLT).

$$
\begin{aligned}
& T P_{n, t}=P_{n, t}^{\prime}+M_{n, t} \\
& D P_{n \neq}=\frac{T P_{n, t}}{S_{n}} \\
& A_{n}=\sqrt{\sum_{i=201:}^{2050}\left(D P_{n, t}-\overline{D P_{n, t}}\right)^{2}} \\
& B_{n}=\frac{\sum_{t=2011}^{2060} M_{n t}}{\max \left(T P_{n t}\right)} \\
& C_{n}=\frac{\sum_{t=2011}^{2000} M_{n}}{\max \left(P_{n+1}^{\prime}\right)-P_{n-2010}}
\end{aligned}
$$

\section{Results}

\subsection{Natural population growth}

China's total population reached 1.265 billion in 2000 according to the 5 th national census. The average natural growth rate for China was $0.565 \%$ from 2000 to 2010 . Should the growth rate are maintained, China's population would increase to 1.337 billion in 2010 . This number is consistent with the population of 1.339 billion resulted from the 6th national census in 2010 . The same method was applied to estimate the natural growth between 2000 and 2010 for each province without consideration of migration. The results were summarized in Table 4 (Column 3). Net migration of each province could be derived by subtracting the cumulative migration reported in the 5th national census from that in the 6 th national census. As summarized in Table 4 (Column 4), the positive sign represents the net immigration population, and the negative sign means the net outmigration. The projected population in 2010 for each province would be obtained by the sum of projected natural growth population and net migration (Column 5). It is impressive for the agreement between projected population for 2010 and the reported population in the 6th national census. The projected population has errors within $5 \%$ as compared to the reported population for each province. The natural growth of future population between 2010 and 2050 were estimated using the same approach.

The growth rate of population projected for the period from 2010 to 2015 does not show significant changes as compared to the rate between 2000 and 2010. The population growth rate for each province tends to slow down after 2015, approaching to zero for most of the 
provinces during the period of 2020-2025. Moreover, the population of some provinces including Beijing, Tianjin, Shanghai, Heilongjiang, Jilin and Shenyang start decreasing. After

Table 4 A comparison between reported population and projected population in 2010

\begin{tabular}{|c|c|c|c|c|c|c|c|}
\hline Province & $\begin{array}{l}\text { Population } \\
2000 \\
\text { (million) }\end{array}$ & $\begin{array}{c}\text { Decade } \\
\text { natural } \\
\text { growth } \\
\text { rate }\end{array}$ & $\begin{array}{c}\text { Projected } \\
\text { natural growth } \\
\text { population } \\
2010 \text { (million) }\end{array}$ & $\begin{array}{l}\text { Reported net } \\
\text { migration } \\
2000-2010 \\
\text { number } \\
\text { (million) }\end{array}$ & $\begin{array}{c}\text { Projected } \\
\text { population } \\
2010 \\
\text { (million) }^{\mathrm{a}}\end{array}$ & $\begin{array}{c}\text { Reported } \\
\text { population } \\
2010 \\
\text { (million) }\end{array}$ & $\begin{array}{c}\text { Percentage } \\
\text { of projected } \\
\text { population } \\
\text { error }^{b}\end{array}$ \\
\hline Beijing & 13.82 & 1.81 & 14.07 & +4.40 & 18.47 & 19.61 & $5.81 \%$ \\
\hline Tianjin & 10.01 & 1.80 & 10.19 & +2.07 & 12.26 & 12.94 & $5.26 \%$ \\
\hline Hebei & 67.44 & 5.99 & 71.48 & -1.81 & 69.67 & 71.85 & $3.03 \%$ \\
\hline Shanxi & 32.97 & 5.90 & 34.91 & -0.51 & 34.4 & 35.71 & $3.67 \%$ \\
\hline Inner Mongolia & 23.76 & 4.03 & 24.72 & +0.33 & 25.05 & 24.71 & $1.38 \%$ \\
\hline Liaoning & 42.38 & 1.11 & 42.85 & +0.09 & 42.94 & 43.75 & $1.85 \%$ \\
\hline Jilin & 27.28 & 2.33 & 27.91 & -0.62 & 27.29 & 27.46 & $0.62 \%$ \\
\hline Heilongjiang & 36.89 & 2.35 & 37.76 & -1.26 & 36.5 & 38.31 & $4.72 \%$ \\
\hline Shanghai & 16.74 & 1.01 & 16.91 & +5.73 & 22.64 & 23.02 & $1.65 \%$ \\
\hline Jiangsu & 74.38 & 2.34 & 76.12 & +3.50 & 79.62 & 78.66 & $1.22 \%$ \\
\hline Zhejiang & 46.77 & 4.44 & 48.85 & +7.76 & 56.61 & 54.43 & $4.01 \%$ \\
\hline Anhui & 59.86 & 6.32 & 63.64 & -4.81 & 58.83 & 59.50 & $1.13 \%$ \\
\hline Fujian & 34.71 & 6.05 & 36.81 & +1.31 & 38.12 & 36.89 & $3.33 \%$ \\
\hline Jiangxi & 41.40 & 8.08 & 44.74 & -1.76 & 42.98 & 44.57 & $3.57 \%$ \\
\hline Shandong & 90.79 & 5.27 & 95.57 & -0.91 & 94.66 & 95.79 & $1.18 \%$ \\
\hline Henan & 92.56 & 5.42 & 97.58 & -5.44 & 92.14 & 94.02 & $2.00 \%$ \\
\hline Hubei & 60.28 & 2.93 & 62.05 & -2.68 & 59.37 & 57.24 & $3.72 \%$ \\
\hline Hunan & 64.40 & 5.35 & 67.84 & -2.55 & 65.29 & 65.68 & $0.59 \%$ \\
\hline Guangdong & 86.42 & 7.65 & 93.03 & +5.98 & 99.01 & 104.30 & $5.07 \%$ \\
\hline Guangxi & 44.89 & 7.98 & 48.47 & -1.33 & 47.14 & 46.03 & $2.41 \%$ \\
\hline Hainan & 7.87 & 9.07 & 8.58 & +0.05 & 8.63 & 8.67 & $0.46 \%$ \\
\hline Chongqing & 30.90 & 3.21 & 31.89 & -1.96 & 29.93 & 28.85 & $3.74 \%$ \\
\hline Sichuan & 83.29 & 3.03 & 85.81 & -1.38 & 84.43 & 80.42 & $4.99 \%$ \\
\hline Guizhou & 35.25 & 8.23 & 38.15 & -2.10 & 36.05 & 34.75 & $3.74 \%$ \\
\hline Yunnan & 42.88 & 8.10 & 46.35 & -1.07 & 45.28 & 45.97 & $1.50 \%$ \\
\hline Tibet & 2.62 & 11.17 & 2.91 & +0.02 & 2.93 & 3.00 & $2.33 \%$ \\
\hline Shaanxi & 36.05 & 4.07 & 37.52 & -0.61 & 36.91 & 37.33 & $1.13 \%$ \\
\hline Gansu & 25.62 & 6.38 & 27.26 & -0.80 & 26.46 & 25.58 & $3.44 \%$ \\
\hline Qinghai & 5.18 & 9.76 & 5.69 & +0.05 & 5.74 & 5.63 & $1.95 \%$ \\
\hline Ningxia & 5.62 & 10.52 & 6.21 & +0.04 & 6.25 & 6.30 & $0.79 \%$ \\
\hline Xinjiang & 19.25 & 10.99 & 21.37 & +0.24 & 21.61 & 21.81 & $0.92 \%$ \\
\hline
\end{tabular}

Note: ${ }^{\text {a }}$ Projected population $2010=$ projected natural growth population $2010+$ reported migration $2000-2010$ number

${ }^{\mathrm{b}}$ Percentage of estimated population error $=\mid$ reported population $2010-$ projected population $2010 \mid /$ reported population 2010

Data source: The 5th National Population Census, 2000, the 6th National Population Census, 2010, and China Statistical Yearbook, 2011

2025, more and more provinces have a shrinking-population. During 2045-2050, all 
provinces have a negative growth except Xinjiang. It is noteworthy that municipalities (except Chongqing) lead in reaching the peaking population, followed by other coastal provinces and some central provinces (Shanxi, Henan, Hunan, Hubei, Jiangxi, Anhui) in China. The final group comprises mostly of remote provinces of western China including Guangxi, Chongqing, Guizhou, Yunnan, Tibet (Xizang), Shaanxi, Gansu, Qinghai, and Ningxia. Xinjiang is a special case that its population becomes flat between 2045 and 2050.

\subsection{Migration at national level}

According to the UN's population forecasting, the urbanization rate in China would grow at an annual rate of $1.2 \%$ from 2010 to 2020 . In other words, China would experience a stable urbanization process in the 2010 s but with a lower average annual growth rate than for the 2000s. The growth rate for urbanization was projected to decrease to $0.8 \%$ during 2020-2030. Once the urbanization rate reaches 70\%, the annual growth rate would decline to $0.4 \%$. At the same time, the expansion of urban population will decrease as the growth of urbanization rate drops. Urban population will increase by 92.39 million between 2010 and 2015, as compared to the increase of 84.78 million between 2015 and 2020. Between 2045 and 2050, the growth in urban population decreases to negative value due to a sharply drop in growth rate projected for years after 2030 (Table 5).

Between 2000 and 2010, migration from rural to urban area accounts for 35\% increase in urban population according to the data reported in the 6 th national census. The experience of developed countries indicated that the population migrations increased first during the process of urbanization and then decreased after completion of the urbanization. China is facing a new situation where intra-provincial migration is the majority of population moving from rural to urban areas, and inter-provincial migration is minor. We assume that inter-provincial migration would reach an equilibrium when urbanization rate reaches $70 \%$. The differences in terms of education, health, medicine, social insurance, and employment are assumed vanish between rural and urban areas and between different provinces. The contributions of rural-tourban migration to the total growth of urban population are $30 \%, 30 \%, 20 \%, 10 \%$,

Table 5 Provincial migration in China

\begin{tabular}{|c|c|c|c|c|c|c|c|c|}
\hline \multirow[b]{2}{*}{ Year } & \multirow{2}{*}{$\begin{array}{c}\text { Total } \\
\text { populatio } \\
n \\
\text { (million) }\end{array}$} & \multirow{2}{*}{$\begin{array}{c}\text { Urban } \\
\text { population } \\
\text { (million) }\end{array}$} & \multirow{2}{*}{$\begin{array}{l}\text { Urbanizatio } \\
\text { n rate }\end{array}$} & \multirow{2}{*}{$\begin{array}{l}\text { Growth in } \\
\text { urban } \\
\text { population } \\
\text { (million) }\end{array}$} & \multicolumn{3}{|c|}{$\begin{array}{c}\text { Migration from rural } \\
\text { to urban area }\end{array}$} & \multirow{2}{*}{$\begin{array}{c}\text { Growth in } \\
\text { migration of } \\
\text { inter-province } \\
\text { (million) }\end{array}$} \\
\hline & & & & & $\begin{array}{l}\text { Inter- } \\
\text { provin } \\
\text { ce }\end{array}$ & $\begin{array}{l}\text { Intra- } \\
\text { provin } \\
\text { ce }\end{array}$ & Total & \\
\hline 2000 & 1259.95 & 456.35 & 0.36 & - & - & - & - & - \\
\hline 2010 & 1339.72 & 669.19 & 0.50 & 212.84 & 34.23 & 40.26 & 74.49 & 46.07 \\
\hline 2015 & 1369.74 & 761.58 & 0.56 & 92.39 & 12.74 & 14.98 & 27.72 & 17.34 \\
\hline 2020 & 1387.79 & 846.36 & 0.61 & 84.78 & 11.69 & 13.75 & 25.42 & 15.91 \\
\hline 2025 & 1395.26 & 911.80 & 0.65 & 65.44 & 6.01 & 7.07 & 13.08 & 8.19 \\
\hline 2030 & 1393.08 & 957.65 & 0.69 & 45.85 & 2.11 & 2.48 & 4.59 & 2.87 \\
\hline 2035 & 1381.59 & 984.45 & 0.71 & 26.80 & 0.00 & 1.61 & 1.61 & 0.00 \\
\hline 2040 & 1360.91 & 998.58 & 0.73 & 14.14 & 0.00 & 0.57 & 0.57 & 0.00 \\
\hline 2045 & 1331.77 & 1004.09 & 0.75 & 5.51 & 0.00 & 0.11 & 0.11 & 0.00 \\
\hline 2050 & 1295.60 & 1001.61 & 0.77 & -2.48 & 0.00 & 0.00 & 0.00 & 0.00 \\
\hline
\end{tabular}

Data source: World Population Prospects, the 2010 and 2011 Revisions

$6 \%, 4 \%, 2 \%$ and $0 \%$ during 2010-2015, 2015-2020, 2020-2025, 2025-2030, 2030-2035, 
2035-2040, 2040-2045 and 2045-2050 respectively. The result shows that the growth in inter-provincial migration sharply reduces from 17 million during the period of 2010-2015 to 2 million during 2025-2030. After the year of 2030, inter-provincial migration has reached regional equilibrium and the net inter-provincial migration was considered as zero.

\subsection{Migration at provincial level}

As illustrated in Figure 1, the net transition probabilities for all provinces in China were ordered from the highest positive values to the lowest negative values. Zhejiang, Guangdong, Shanghai, Beijing, Jiangsu, Tianjin and Fujian are the major net in-migration provinces in 2010. These migration-host provinces are all located in the east coast, with high socioeconomic development level. On the other hand, Henan, Anhui, Hubei and Hunan are the migration-source provinces in 2010, with the largest net transition probabilities respectively of $-12.5 \%,-11.0 \%,-6.1 \%$ and $-5.8 \%$. Nearly all the migration-source provinces are located in central or northeast China with large number of surplus rural labor force. In contrast to these two categories of provinces, which have high absolute values of net transition probability, one third of the provinces maintains a net migration balance with probabilities fluctuating within the range of $-1 \%$ and $1 \%$. In addition, most of the total populations of these provinces were relatively small, and therefore their net-migration is negligible.

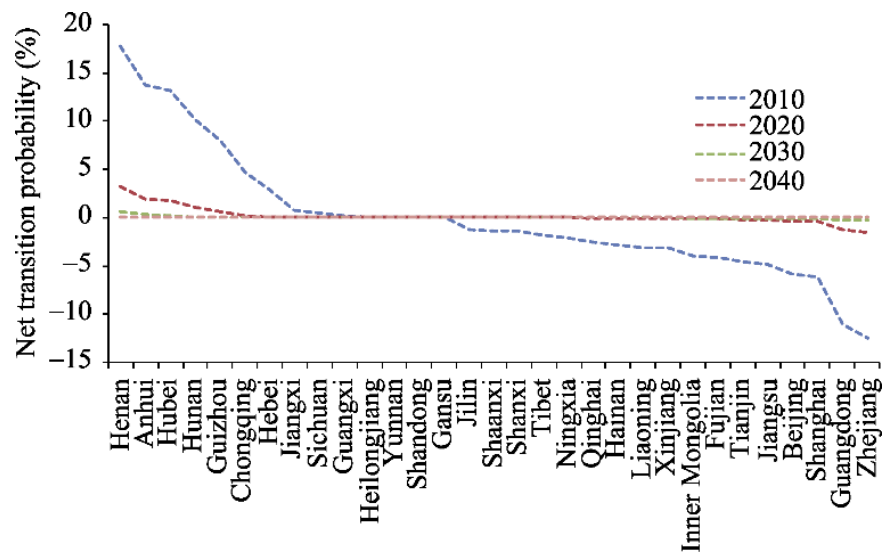

Figure 1 Net transition probability of each province

Net transition probability at provincial level for 2015, 2020, 2025, 2030, 2035 and 2040 were estimated using the Markov chain approach. The results indicate that net transition probability declines dramatically between 2010 and 2020, although maintaining the same migration direction. The migration probabilities for all provinces approach zero after 2030, reflecting the assumption that inter-provincial migration reaches a regional equilibrium when urbanization rate reaches $70 \%$ in 2030 .

\section{Spatial pattern of Chinese provincial population in 2010-2050}




\subsection{Evolution of provincial population density}

Population density of each province for 2010, 2015, 2020, 2030, 2040 and 2050 was illustrated in Figure 2. The results suggested that the distribution of population in China maintains similar spatial pattern for next four decades. East China has the highest population density and followed by central China, northeast China and west China. Four provinces in the east, Shanghai, Beijing, Tianjin and Jiangsu, will remain the top in terms of population density, with an averaged population density of 3540, 1411, 1114 and 736 persons per $\mathrm{km}^{2}$, respectively; Shandong was No.5 in 2010 and will fall to No.7 in 2020, surpassed by Guangdong and Zhejiang in 2020. Hebei ranked No.10 in 2010, and No. 9 in 2020. The rank of Fujian increased from No.14 in 2010 to No.11 in 2050. As to southeast China, Hainan has the lowest population density, but it will surpass Liaoning in 2040 and Hubei in 2050, consequently reaching No.15 with an averaged population density of 269 persons per $\mathrm{km}^{2}$. In central China, Henan and Anhui have kept consistent in No.8 and No.10 respectively since 

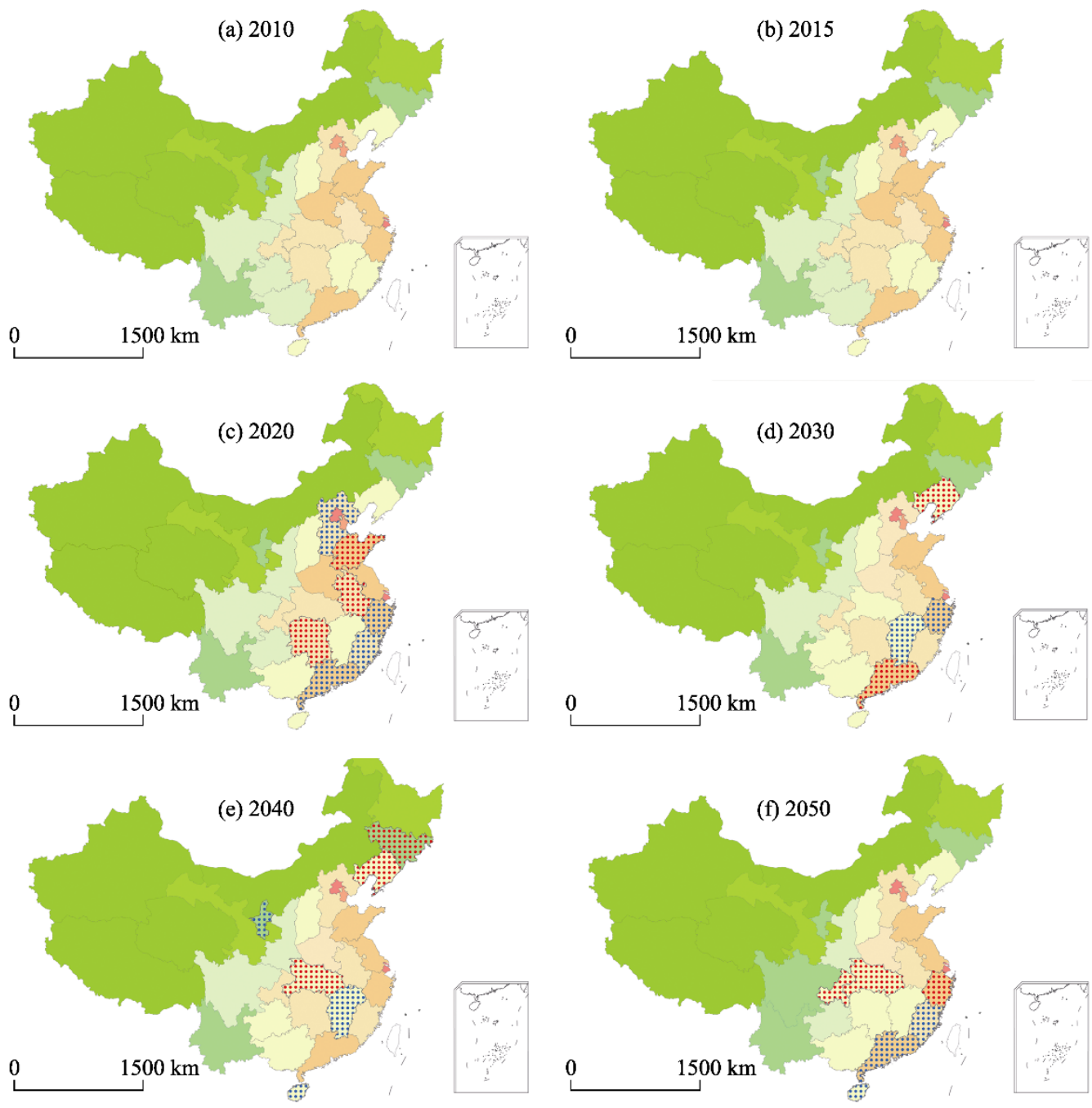

Popolation density (person $/ \mathrm{km}^{2}$ )

\begin{tabular}{l|l|l|l|l|l}
\hline$<25$ & $100-150$ & $200-300$ & $400-500$ & $800-1200$ & $\because: \because::$ Ascend \\
$25-100$ & $150-200$ & $300-400$ & $500-800$ & $>1200$ & $\because: \because: 3$ Descend
\end{tabular}

Figure 2 Provincial population density and its ranking change in 2010-2050

2015, with an averaged population density of 502 and 377 persons per $\mathrm{km}^{2}$, respectively. Hunan drops from No.12 to No.13 from 2010 to 2020, over the same period Hubei moves downwards from No.13 to No.16. Jiangxi rises to No. 14 after 2030. Shanxi keeps at No.18 all the time; The averaged population densities are ranging from 200 to 300 persons per $\mathrm{km}^{2}$ in Hunan, Hubei, Jiangxi and Shanxi. In northeast China, Liaoning drops 1 position separately in 2030 and 2035 from No.15 to No.17, with an averaged population density of 278 persons per $\mathrm{km}^{2}$, while Jilin would drop from No.23 to No.24 in 2035, with an averaged population density of 137 persons per $\mathrm{km}^{2}$. Heilongjiang keeps at No.26 over the entire study period, with an averaged population density of 80 persons per $\mathrm{km}^{2}$. In west China, almost all the provinces keep ranks below No.20 over the study period, except for Ningxia and Chongqing 
with a slight change between 2040 and 2050. The last three provinces are Xinjiang, Qinghai and Tibet, where the averaged population densities are 15, 9 and 3 persons per $\mathrm{km}^{2}$, respectively.

\subsection{Regional characteristics}

Based on evolution of population density change in each province, the ratio of new accumulated net-migration to the peaking population and new accumulated natural population growth, we divide China into three types of region: FCPR, LCPR and IPR. Furthermore, we classify FCPR into three types: NILT, NELT and NGLT. In addition, we categorize LCPR into net immigration type (NIT) and net emigration type (NET). The results are summarized in Table 6. China's population is projected to increasingly concentrate in NILT area, which receives nearly $99 \%$ of newly accumulated immigration population. NELT area accounts for $75 \%$ of emigration population, including Henan, Anhui, Chongqing and Hubei. In LCPR, Fujian and Hainan belong to NIT, with growth in net-migration population as small as $1 \%$. NET area will contribute $18 \%$ of emigration in future, while the percentage is significantly lower than that for NELT area in FCPR region. Population density for the majority of west provinces is likely to remain low and slightly declining.

Table 6 Regional type and its characters of spatial pattern

\begin{tabular}{|c|c|c|c|c|c|c|c|}
\hline \multicolumn{2}{|c|}{ Regional type } & \multicolumn{3}{|c|}{ Criterion } & \multirow{2}{*}{$\begin{array}{l}\text { Ratio of new } \\
\text { accumulated } \\
\text { floating } \\
\text { population } \\
(\%)\end{array}$} & \multirow{2}{*}{$\begin{array}{c}\text { Ratio of new } \\
\text { accumulated } \\
\text { natural } \\
\text { population } \\
\text { growth }(\%)\end{array}$} & \multirow{2}{*}{ Province } \\
\hline Class & Sub-classes & A & B & $\mathrm{C}$ & & & \\
\hline \multirow{3}{*}{$\begin{array}{l}\text { Fast } \\
\text { Changing } \\
\text { Populated } \\
\text { Region }\end{array}$} & $\begin{array}{l}\text { Net } \\
\text { immigration } \\
\text { leading type }\end{array}$ & \multirow{3}{*}{$\mathrm{A}>10$} & $b>5 \%$ & $c>>1$ & 99 & 18 & $\begin{array}{l}\text { Beijing, Tianjin, } \\
\text { Jiangsu, Shanghai, } \\
\text { Zhejiang, Guangdong }\end{array}$ \\
\hline & $\begin{array}{l}\text { Net emigration } \\
\text { leading type }\end{array}$ & & $\mathrm{B}<-5 \%$ & $\mathrm{c}<<-1$ & -75 & 14 & $\begin{array}{l}\text { Henan, Anhui, } \\
\text { Chongqing, Hubei }\end{array}$ \\
\hline & $\begin{array}{l}\text { Natural growth } \\
\text { leading type }\end{array}$ & & $\mathrm{b} \approx 0 \%$ & $|\mathrm{c}| \approx 0$ & -1 & 6 & Liaoning, Shandong \\
\hline \multirow{2}{*}{$\begin{array}{l}\text { Low } \\
\text { Changing } \\
\text { Populated } \\
\text { Region }\end{array}$} & $\begin{array}{l}\text { Net } \\
\text { immigration } \\
\text { type }\end{array}$ & \multirow[b]{2}{*}{$5<a<10$} & $0<\mathrm{b}<5 \%$ & $0<\mathrm{c}<1$ & 1 & 5 & Fujian, Hainan \\
\hline & $\begin{array}{l}\text { Net emigration } \\
\text { type }\end{array}$ & & $-5 \%<b<0$ & $-1<\mathrm{c}<0$ & -18 & 31 & $\begin{array}{l}\text { Hebei, Shanxi, Jilin, } \\
\text { Heilongjiang, Hunan, } \\
\text { Jiangxi, Guangxi, } \\
\text { Sichuan, Shaanxi }\end{array}$ \\
\hline \multicolumn{2}{|c|}{ Inactive Populated Region } & $a<5$ & $0<\mathrm{b}<5 \%$ & $|\mathrm{c}| \approx 0$ & -6 & 26 & $\begin{array}{l}\text { Guizhou, Yunnan, } \\
\text { Ningxia, Gansu, Inner } \\
\text { Mongolia, Xinjiang, } \\
\text { Qinghai, Tibet }\end{array}$ \\
\hline
\end{tabular}

Note: A represents variance of population density change; B denotes the ratio of new accumulated net-migration to maximum of total population amount; $\mathrm{C}$ demonstrates the ratio of new accumulated net-migration to maximum of natural growth population.

Figure 3 summarizes the evaluation of population density for the FCPR region in China. The ratio of new accumulated net-migration to the peaking population is above $10 \%$ in NELT area, with the highest number in Beijing (55\%) followed by Shanghai (47\%). As illustrated in Figure 3, the population densities in the six provinces in NELT first increase and then decrease reflecting the change of net immigration population amount. For Tianjin and Jiangsu, population densities reach the peak in 2020 , with 1171 and 771 persons per $\mathrm{km}^{2}$, respectively. For Shanghai, Beijing and Zhejiang, population densities reach the peak in 2030, with 3825, 
1499 and 697 persons per $\mathrm{km}^{2}$ respectively. The maximum population densities for these three provinces are $36 \%, 25 \%$, and $35 \%$ higher than the corresponding values for 2010 . For Guangdong, population density will reach the peak in 2035, with 684 persons per $\mathrm{km}^{2}$ as compared to the value, 570 persons per $\mathrm{km}^{2}$ for 2010 . The ratio of accumulation emigration to the peaking population is below $15 \%$ in NELT area, with the highest ratio in Anhui (38\%) and the second highest number in Henan (27\%). The population densities in four provinces keep decreasing over the study period. For Henan, Anhui, Chongqing and Hubei, population densities in 2050 will decrease to 450, 348, 299 and 262 persons per $\mathrm{km}^{2}$ respectively. For Liaoning and Shandong, population densities drop to 243 and 592 persons per $\mathrm{km}^{2}$ in 2050 , respectively.

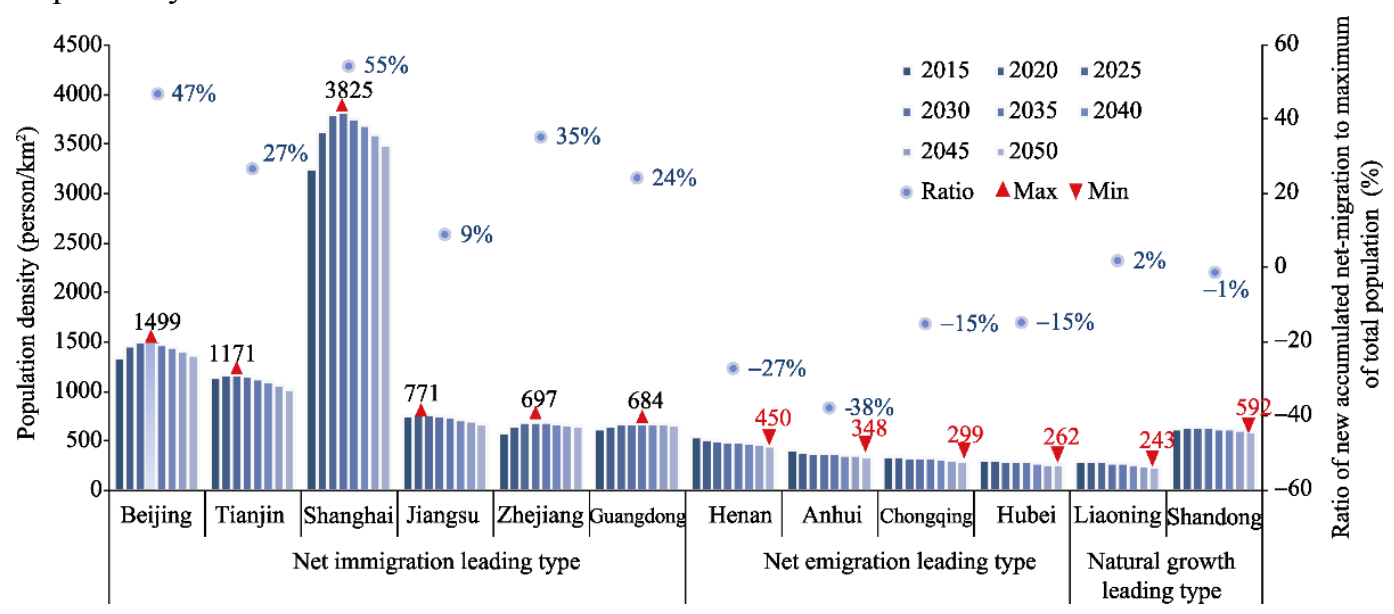

Figure 3 Population densities forecasting for fast changing populated region in 2010-2050 Note: “_” denotes there's net emigration population

\section{Conclusions}

We improved the macro-level strategy for population forecasting, and applied it to estimate the future natural growth and migration of population at provincial level in China. A comparison between the estimated natural growth and reported statistics from 2000 to 2010 suggested that the method proposed in this paper is applicable to make population forecasting. The method can be easily tailored for the county-level studies. It should be noted that the method based on the averaged natural growth to forecast the natural growth of population. Inter-provincial migration is assumed to reach an equilibrium after urbanization rate reaching $70 \%$ in 2030 . The results suggested that inter-provincial migration probability is deduced to be around zero after 2030 through a Markov chain approach, which is consistent with our assumption.

The results from the analysis of the spatial pattern and evolution trend of Chinese provincial population suggest that the overall spatial pattern of Chinese population will be maintained in next four decades, with the east area having the highest population density and followed by central area, northeast and west area. Four provinces in the east, Shanghai, Beijing, Tianjin and Jiangsu, will remain the top in terms of population density in China, and Xinjiang, Qinghai and Tibet will continue to have the lowest density of population. Based on the analysis of the future trends in provincial population densities, we introduced an index 
system to classify the Chinese provinces into three categories: the FCPR, LCPR, and IPR regions. China's population is projected to increasingly concentrate in NILT area where receives nearly $99 \%$ of new accumulated floating population. Policy-making and planning process in China should take into account the changes of population pattern in the FCPR region.

\section{References}

Andrew M I, 1984. Projection, forecast, and plan on the future of population forecasting. Journal of the American Planning Association, 50(2): 208-221.

Bach R L, Schraml L A, 1982. Migration, crisis, and theoretic conflict. International Migration Review, 16: 320-341.

Booth H, Hyndman R J, Tickle L et al., 2006. Lee-Carter mortality forecasting: A multi-country comparison of variants and extensions. Demographic Research, 15(9): 289-310.

Chen Daiyun, 2012. Improve policies to realize reasonable distribution of floating population. People's Daily. $\mathrm{http}: / /$ opinion.people.com.cn/GB/17805735.html. (in Chinese)

Gans H A,1999. Population Forecasting 1895-1945: The Transition to Modernity. Dordrecht, The Netherlands: Kluwer.

Harris R S, Moore E G, 1980. An historical approach to mobility research. Professional Geographer, 32: 22-29.

Hyndman R J, Ullah M S, 2007. Robust forecasting of mortality and fertility rates: A functional data approach. Computational Statistics \& Data Analysis, 51: 4942-4956.

Kenneth B, Wendling R, 1980. The national-regional impact evaluation system: A spatial model of US economic and demographic activity. Journal of Regional Science, 20: 143-158.

Keyfitz N, 1968. Introduction to the Mathematics of Population. Reading, Mass: Addison-Wesley.

Keyfitz N, Caswell H, 2005. Applied Mathematical Demography. 3rd ed. New York: Springer.

Liu Shenghe, Deng Yu, Hu Zhang, 2010. Research on classification methods and spatial patterns of the regional types of China's floating population. Acta Geographica Sinica, 65(10): 1187-1197. (in Chinese)

Long J F, 1985. Migration and the phase of population redistribution. Journal of Development Economics, 17: $29-42$.

Ma Hailing, Zheng Hong, 2011. Implication of sixth census to demographic dividend. people.com.cn. http://www.people.com.cn/h/2011/1231/c25408-1507470959.html. (in Chinese)

Nakicenovic, 2000. Special Report on Emissions Scenarios, IPCC, Geneva and Cambridge University Press.

National Bureau of Statistics (NBS), 2001. China Statistical Yearbook. Beijing: China Statistics Press. (in Chinese)

National Bureau of Statistics (NBS), 2011. China Statistical Yearbook. Beijing: China Statistics Press. (in Chinese)

Stauffer D, 2002. Simple tools for forecasts of population ageing in developed countries based on extrapolations of human mortality, fertility and migration. Experimental Gerontology, 37: 1131-1136.

Thomas P, 1981. An econometric model for forecasting regional population growth. International Regional Science, 6: $53-70$.

Wood C H, 1982. Equilibrium and historical-structural perspectives on migration. International Migration Review, 6: $298-319$.

Zhang Kevin Honglin, Song Shunfeng, 2003. Rural-urban migration and urbanization in China: Evidence from time-series and cross-section analyses. China Economic Review, 14: 386-400.

Zhu Baoshu, 2011. The changes in fertility of the migrants in the urban from the rural. South China Population, 26(6): 42-50. (in Chinese) 